\title{
Developing a framework for the assessment of the Australian research system
}

\author{
ALBERT PATAJO
}

\section{Abstract}

The aim of this research was to develop a framework for the holistic assessment of the Australian research system. Through the identification of indicators and the presentation of data from metrics that encompassed these indicators, this research presented an accurate portrayal of the performance of the Australian research system. This research was developed in response to the Boosting the Commercial Returns from Research report that was presented by the Australian Government in 2014. The current assessment tools are fragmented and do not provide a holistic approach to the evaluation of the Australian research system. Indicators are used to provide a quantifiable analysis of the research system. The indicators used in this research project were resourcing, quality, engagement, return on investment and responsiveness. These indicators had been identified by the Department of Education and other government research. Research was conducted through data mining available databases and through data requested from organisations. These data were presented against the Organisation for Economic Co-operation and Development (OECD) average in order to determine how Australia was progressing internationally. The quality of Australian research is stronger than the OECD average, with Australian research receiving more citations per publication and more publications per researcher. However, Australia should improve on resourcing its research system through an increase in investment in research to remain competitive, as well as providing incentives for industry collaboration and research commercialisation. This article makes several key recommendations for improving research evaluation frameworks and data collection. The collection of sufficiently robust data will ensure that future frameworks are able to accurately assess the Australian research system. 


\section{Introduction}

The research system in Australia drives knowledge creation and innovation. In 2014, the Australian Government presented the Boosting the Commercial Returns from Research paper that outlined the need to develop an assessment framework to assess the research system holistically. ${ }^{1}$ This article presents the reasoning behind such an assessment and develops a framework to which the research system in Australia can be evaluated.

\section{Developing an assessment framework}

\section{Why do we need to assess the research system?}

Australia's research sector has been regarded as a high performer by the Organisation for Economic Co-operation and Development (OECD). ${ }^{2}$ The research sector is incredibly important, receiving approximately $\$ 9$ billion in funding from the Australian Government annually, ${ }^{3}$ and has the potential to drive innovation and economic growth and address regional and global challenges; it also has numerous benefits to society at large.

Given the large size of this investment and its potential, it is vital that the current research infrastructure is operating effectively and maximising the utility of the funding. In order to make this assessment, a framework should be developed that allows for the functionality of the system to be appropriately assessed.

There are several assessment tools currently in place that allow for a fragmented assessment of the research system. These assessment tools provide an indication for a discrete part of the research system and are limited by their varied approach, differences in coverage and timing, as well as the ability to make international comparisons.

\footnotetext{
1 Department of Education and Department of Industry (2014), Boosting the Commercial Returns from Research. Available from submissions.education.gov.au/Forms/higher-education-research/Documents/Boosting\%20 Commercial\%20Returns\%20from\%20Research\%20\%20-\%2024102014.pdf.

2 Office of the Chief Economist and Department of Industry (2012), Australian Innovation System Report 2012. Available from industry.gov.au/Office-of-the-Chief-Economist/Publications/Policy/Australian InnovationSystemReport/AISReport2012.pdf.

3 Department of Education and Department of Industry (2014), Boosting the Commercial Returns from Research. Available from submissions.education.gov.au/Forms/higher-education-research/Documents/Boosting\%20 Commercial\%20Returns\%20from\%20Research\%20\%20-\%2024102014.pdf.
} 


\section{What assessment tools are currently in place?}

\section{National Survey of Research Commercialisation}

The National Survey of Research Commercialisation (NSRC) collects data on research commercialisation outputs from publicly funded research organisations, universities, medical research institutes and cooperative research centres. ${ }^{4}$

The NSRC consists of 26 main questions, capturing data on research expenditure, intellectual property, research contracts, consultancies and direct sales, and skill development. ${ }^{5}$ It is published every two years, and the data is used by the Commonwealth to support policy developments.

Data from NSRC is benchmarked with international data from the United States (US), Canada and the United Kingdom (UK) to allow for international comparison between Australia and these countries. ${ }^{6}$

\section{Higher Education Research Data Collection}

The Department of Education collects data on research income and research publication data, which universities submit each year. ${ }^{7}$ The purpose of Higher Education Research Data Collection (HERDC) is to provide guidance on the allocation of research funding for universities.

Publications data is grouped into four categories: books, book chapters, journal articles and conference publications. Research income is categorised by Australian competitive grants, other public sector income, industry and other research income, and Cooperative Research Centre (CRC) research income. These data allow for the assessment of university output based on their funding amounts.

International comparison of these data is impractical. Research in Australia is not solely limited to universities themselves, and universities internationally receive higher levels of funding. While it is possible to make assessment based on public sector funding and university output, this information would only be useful when assessing universities and not the research system holistically.

\footnotetext{
4 Department of Industry and Science (2015), National Survey of Research Commercialisation 2015 Review Report. Available from industry.gov.au/innovation/NSRC/Policy/Documents/Final-NSRC-Review-Report.pdf.

5 Ibid.

6 Ibid.

7 Department of Education and Training, Higher Education Research Data Collection. Reports available from archive.arc.gov.au/file-search/ERA?level_1=ERA\&level_2=2012\&level_3=National\%20Report\&sort=asc\& order=Document $\% 20$ Name.
} 


\section{Excellence in Research Australia}

The Australian Research Council (ARC) conducts the Excellence in Research Australia (ERA) evaluation, which assesses the quality of research activity at higher education institutes. ${ }^{8}$ ERA provides for a framework to determine if university research is at or above world standard. ${ }^{9}$

Beginning in 2010, ERA has collected data on the quality, volume, application and recognition of research activities to make this determination. These metrics are examined in light of their contributions to the field of research on a performance benchmark of $1-5$.

ERA is one of the most comparable research rankings available for Australian research. Data for each indicator is assessed against its international counterpart, allowing for a clear picture of Australia's research standing internationally. However, similar to HERDC, ERA only assesses university institutes, which leaves a large gap in the assessment of research conducted by other research organisations.

\section{University rankings}

Universities in Australia are ranked by several different ranking systems, the most popular three being the QS, Times Higher Education and the Academic Ranking of World Universities. Each ranking system uses varied methodologies, with emphasis on different metrics to create their ranking.

Whilst there is some emphasis on the quality of the research conducted by universities, these ranking systems only give a very small indication of how the research conducted by universities compares to other countries. Another issue with using these rankings to assess the research system is that the data used for these metrics are not often freely available for independent assessment, or are difficult to find in isolation from the rankings themselves.

Lastly, university rankings themselves do not offer a holistic view of the research system, which is problematic when used as a basis for driving policy discussions in regards to funding research and innovation in Australia.

8 Australian Research Council and Commonwealth of Australia, The Excellence in Research for Australia (ERA) Initiative. Available from: www.education.gov.au/higher-education-research-data-collection (Accessed: 17 September 2015).

9 Ibid. 


\section{How have other countries assessed their research systems?}

\section{European Union}

In the European Union (EU), the assessment of research system is completed by ERAWATCH. This assessment is completed annually by the European Commission and consists of an examination of each country present in the EU.

The framework is quite basic in its approach, looking at four broad indicators: human resources, financing, excellence and output. ${ }^{10}$ These basic indicators are broken down into several metrics per indicator to provide a holistic approach to the assessment. This framework has been shown to be easily adaptable due to its broadness, allowing for evaluations of different countries under the same metrics for direct comparison.

\section{United Kingdom}

In addition to ERAWATCH, the UK conducts an assessment through its Research Excellence Framework (REF). The REF is used to allocate research grants and consists of an examination of the quality, vitality and impact of the research. ${ }^{11}$

The aim of REF is to direct research funding to high performing researchers and research areas and to remove it from researchers who are weak performers. Furthermore, this movement of funds is done without consideration of research priorities, which presents an issue for assessing the responsiveness of the system. ${ }^{12}$

\section{United States}

In the US, assessment of research systems exist predominately for universities, with no formal framework for a holistic assessment of the entirety of their research system. ${ }^{13}$ Currently, the only assessment outside of university research is prospective,

\footnotetext{
10 Paul Cunningham (2014), ERAWATCH Country Reports 2013: United Kingdom, European Commission. Available from rio.jrc.ec.europa.eu/sites/default/files/riowatch_country_report/ERAWATCH\%20Country\%20 Report\%20UK\%202013.pdf.

11 OECD Innovation Policy Platform (n.d.), OECD Issue Brief: Research Organisation Evaluation. Available from www.oecd.org/innovation/policyplatform/48136330.pdf (accessed 1 October 2015).

12 Ibid.

13 The Center for Measuring University Performance (2012), The Top American Research Universities Annual Report 2012. Available from mup.asu.edu/sites/default/files/mup-pdf/MUP-2012-Top-American-ResearchUniversities-Annual-Report.pdf.
} 
rather than retrospective in nature. ${ }^{14}$ This means research is evaluated at a project level, occurring when programs are selected for funding based on academic quality, anticipated benefits and adherence to strategic research goals. ${ }^{15}$

This prospective assessment has several benefits: it allows for research funding allocation to be distributed according to overarching goals and also for research that has anticipated commercial outcomes to be prioritised, ensuring that research is translated into tangible benefits.

\section{What indicators should be used to assess the research system?}

The Australian Government Department of Education and Training identified several broad characteristics of a research system that could be used to assess the system holistically. These characteristics represent the key aspects of the research system, and are applicable to the institutions within the system itself.

The strength of these characteristics lies in the robustness of the indicators that can be used for assessment and the ability for international comparison.

\section{Resourcing}

Research systems must consistently have a high level of resourcing from numerous sectors in order to ensure the system remains healthy. ${ }^{16}$ The REF report indicated that resourcing takes the form of both financial investment and human capital (researcher, higher degree research graduates). ${ }^{17}$

Resourcing input shows a number of important policy undertones of the research system, such as the importance of research to a particular country, the strengths of its public and private sector research and its ability to develop and educate researchers. ${ }^{18}$ Furthermore, by examining the resourcing against metrics, such as the number of full-time equivalent (FTE) researchers and the outputs of the system, the efficiency of the system can be assessed.

14 OECD Innovation Policy Platform (n.d.), OECD Issue Brief: Research Organisation Evaluation. Available from www.oecd.org/innovation/policyplatform/48136330.pdf (accessed 1 October 2015).

15 Ibid.

16 Paul Cunningham (2014), ERAWATCH Country Reports 2013: United Kingdom, European Commission. Available from rio.jrc.ec.europa.eu/sites/default/files/riowatch_country_report/ERAWATCH\%20Country\%20 Report\%20UK\%202013.pdf, p. 25.

17 Ibid., p. 23.

18 Ibid. 
This article will examine resourcing in regards to several metrics: the gross expenditure of research and development, business expenditure on research and development, government expenditure on research and development, higher education funding and the number of both FTE researchers and higher research degree (HDR) graduates.

These metrics will be compared to the OECD average to allow for assessment of how Australia is faring internationally in regards to the resourcing of its research system.

\section{Quality}

Research quality is the most definitive measure of the strength of a research system. It indicates the standard of research conducted by the country and whether a country is competitive in its research and development. ${ }^{19}$ Quality refers to the citations and publications.

The quality of a research system indicates a number of strong aspects of the system itself, such as the originality of the research conducted and the novelty of the discoveries made, the comprehensiveness of the methodology and the value of the research to other researchers and end users.

This article will examine quality with respect to several metrics: the number of publications per capita and the number of citations per capita.

As with resourcing, an international comparison allows conclusions to be developed on how Australia fares compared to OECD countries. This allows us to determine whether we have been competitive internationally and if we will continue to be competitive in the future.

\section{Engagement}

Research and development does not operate in a vacuum; in order to have a strong research system, there must be strong engagement between the research system and other sectors. Engagement takes the form of knowledge sharing with other research organisations, collaborations with industry and interactions between the research system and the public. ${ }^{20}$

19 Higher Education Funding Council for England (2014), Research Excellence Framework 2014: The results. Available from www.ref.ac.uk/media/ref/content/pub/REF\%2001\%202014\%20-\%20full\%20document.pdf.

20 ATSE (2015), Research Engagement for Australia: Measuring Research Engagement Between Universities and EndUsers. Available from www.atse.org.au/content/publications/reports/industry-innovation/research-engagement-foraustralia.aspx. 
This article will examine research engagement through the number of publications with industry co-authors and international collaboration. ${ }^{21}$ Due to the intangible nature of many of the possible indicators or the difficulty in obtaining data on possible metrics, it is hard to form a complete picture on Australia's comparative situation. Nonetheless, engagement remains an important aspect of the research system and should be considered when developing an assessment framework of the research system.

\section{Return on investment}

Due to the resourcing and investment of the research system by government and industry, there is an expectation that the research leads to maximum social, economic and environmental benefits. ${ }^{22}$ This expectation is further heightened in that there must be consideration for the efficiency of the research conducted.

Return on investment is one of the most evident strengths of a research system. It highlights clear benefits to research and development, and provides a basis for further funding. ${ }^{23}$ Translation of research into inventions such as new products, processes and technologies contributes to both economic growth and productivity. ${ }^{24}$

This article will examine return on investment through Australia's research commercialisation metrics such as patent developments and researcher efficiency.

There are several difficulties in assessing the return on investment of research due to the timelines associated with commercialisation. Despite this difficulty, return on investment is still one of the most important aspects of a research system due to its clear relation between resourcing and the output of the system itself.

\section{Responsiveness}

The last important indicator developed by the Department of Education (DoE) in the assessment framework is the responsiveness of the research system. In order for a research system to optimise its societal and economic benefits, a research system must be dynamic in its ability to address key regional, national and global challenges and adapt to changing research priorities. ${ }^{25}$

21 Office of the Chief Scientist (2012), Health of Australian Science Report. Available from www.chiefscientist.gov. $\mathrm{au} / 2012 / 05 /$ health-of-australian-science-report-2/.

22 Department of Industry (2014), Australian Innovation System Report, p. 16.

23 Ibid., p. 37.

24 Zvi Griliches (1998), R\&D and Productivity: The Economic Evidence, University of Chicago Press, Chicago.

25 Chief Scientist of Australia (2014), Strategic Science and Research Priorities. Available from www.chiefscientist. gov.au/wp-content/uploads/STRATEGIC-SCIENCE-AND-RESEARCH-PRIORITIES_181214web.pdf (Accessed: 03 August 2015). 
However, a difficulty in measuring the responsiveness of the research system arises due to these changes being reactive to political or external events, rather than proactive responses. These short-term reactionary changes make it difficult to collect data for the same reason it is difficult to collect data on return on investment of research. This article has assessed responsiveness by examining the funding changes to NPR.

\section{Assessing the Australian research system}

\section{Methodology}

This article has established a framework for the assessment of the research system based upon recommendations from the DoE and international frameworks. Furthermore, the DoE identified several metrics that fell within each indicator that provided for the assessment to be conducted. These metrics are fragmented in approach, but assessed together provide a holistic picture of the indicator itself.

Data collection consisted of data mining government reports, statistics from HERDC, the Australian Bureau of Statistics (ABS), ERA, UNESCO, OECD, IP Australia, CSIRO, ERAWATCH and the World Bank. These data were compiled and transformed in order to portray the current state of the research system with respect to that particular indicator.

Data was collected from pre-existing sources due to time constraints and the impracticality of data collection for this research. Well-resourced organisations and government departments had this data freely available, and this data was used for making the assessment.

In order to develop international comparisons, it was preferable that data was in the form of 'per capita' and that there was comparable data on other countries. International comparisons were made against the OECD average due to similarities between Australia and the countries in the OECD socioeconomic status. It would be inappropriate to make comparisons between Australia and non-OECD countries due to differences in GDP, size, culture and government priorities.

Lastly, this article does not attempt to explain trends in the data: rather it makes presentations on these trends. This is for a number of reasons. First, it would exceed the scope of the project in terms of resources, time and practicality. Second, the examination of these trends and attempts to explain them would be considered a research project in themselves. Third, it is not necessary to explain these trends to make the assessment itself. 


\section{Resourcing}

Gross expenditure on research

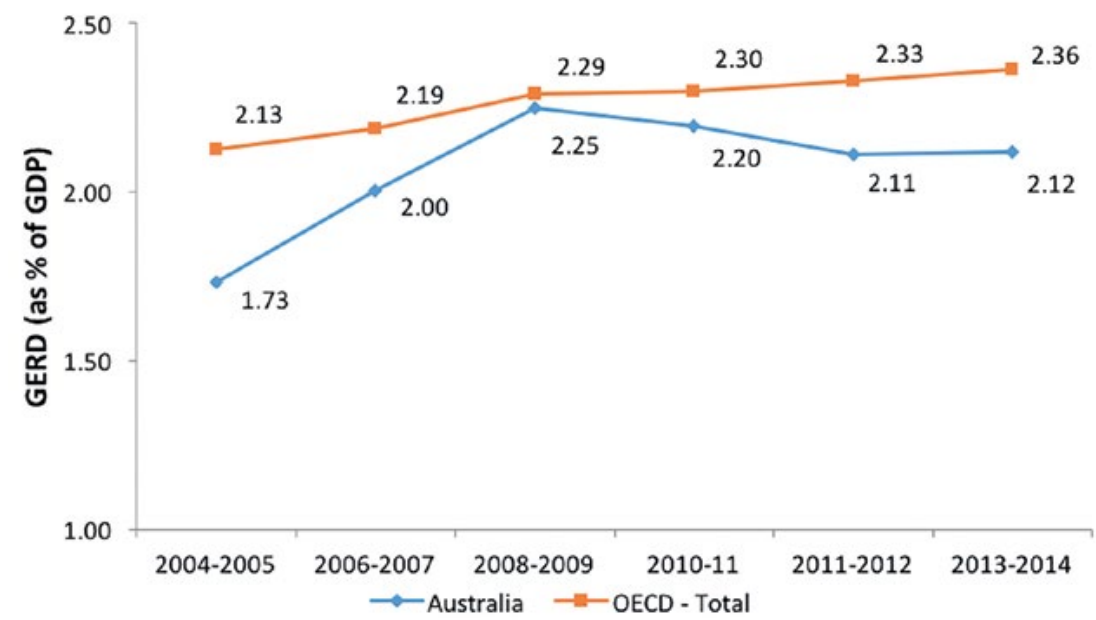

Figure 1: Australian/OECD comparison of gross expenditure on research and development (GERD)

Australia: There has been an increase in research expenditure over the past 10 years from $1.73 \%$ of the GDP to $2.12 \%$ of the GDP, an increase of $0.39 \%$ over 10 years. OECD Average: Similarly, there has been an increase in the last 10 years in the OECD average from $2.13 \%$ to $2.36 \%$, which is an increase of $0.23 \%$.

Data: Australian Bureau of Statistics.

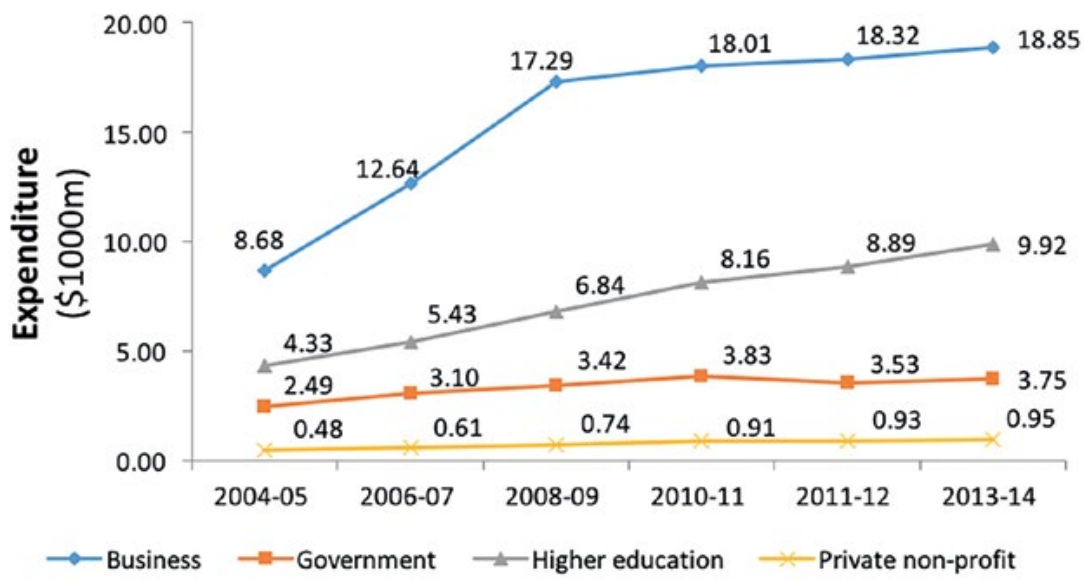

Figure 2: Australian gross expenditure on research and development by sector

Australia: The $0.39 \%$ increase in research and development in the past can be explained by the increased investment in research by the business sector. OECD Average: Comparable OECD data was not available.

Data: Australian Bureau of Statistics. 


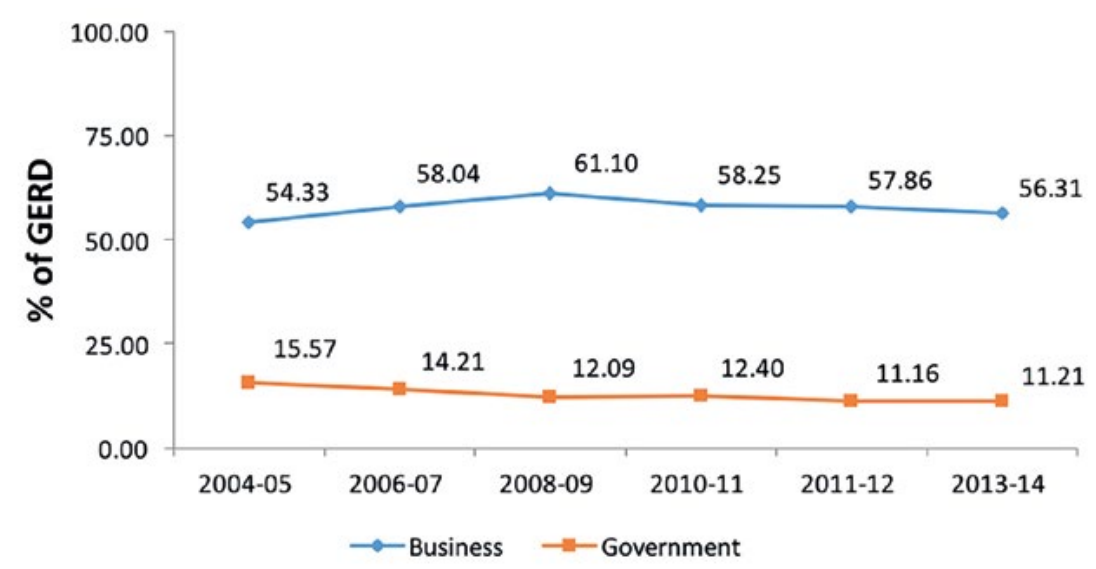

Figure 3: Comparisons between \% gross domestic expenditure on research and development (GERD) financed by government vs \% GERD financed by business

Australia: Figure 3 highlights the increase in business expenditure over the past 10 years. However, this increase in expenditure only accounts for a rise of $1.98 \%$ of the total expenditure on research and development in the last 10 years. OECD Average: Comparable OECD data was not available. Data: Australian Bureau of Statistics.

\section{Business expenditure on research and development}

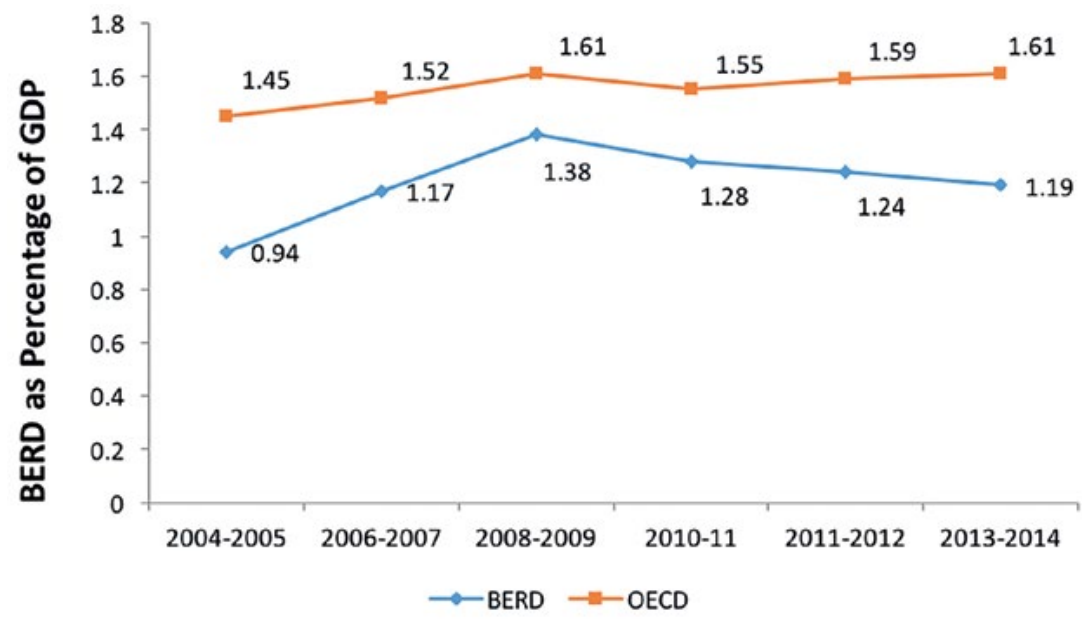

Figure 4: Comparison Australia/OECD business expenditure on research and development (BERD)

Australia: Figures 2 and 3 have shown that the largest investor in research in Australia has been the business sector. Despite this, Australia has consistently trailed behind the OECD; however, there has been an increase of $0.25 \%$ over the past 10 years. OECD Average: Figure 1 has shown that the OECD invests more money in research than Australia. Despite Figure 2 not having comparable OECD data, the above graph highlights that the OECD performs better in businesses investing in research.

Data: Australian Bureau of Statistics. 


\section{Higher education expenditure on research and development}

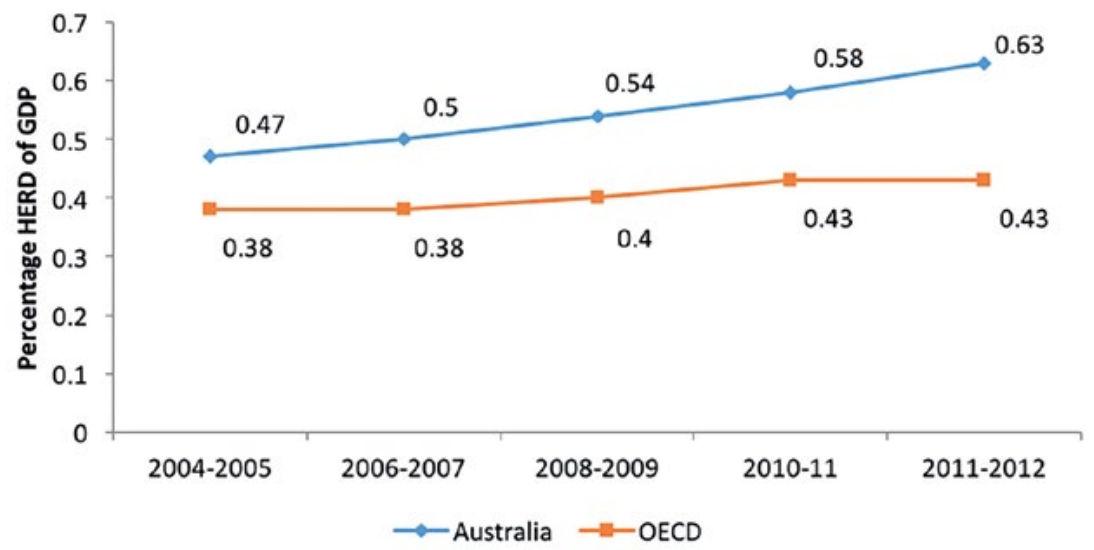

Figure 5: Comparison Australia/OECD higher education research and development (HERD)

Australia: Figure 2 shows that higher education has the second highest investment in research in Australia. Figure 5 highlights that this investment has seen a steady increase every year between 2004 and 2012 (0.16\% over the eight-year period). OECD Average: There has been an increase of $0.5 \%$ in the 2004-2012 period. Despite the OECD investing more money into research than Australia, Australia performs better in the higher education research sector in regards to resourcing.

Data: Australian Bureau of Statistics.

Government expenditure on research and development

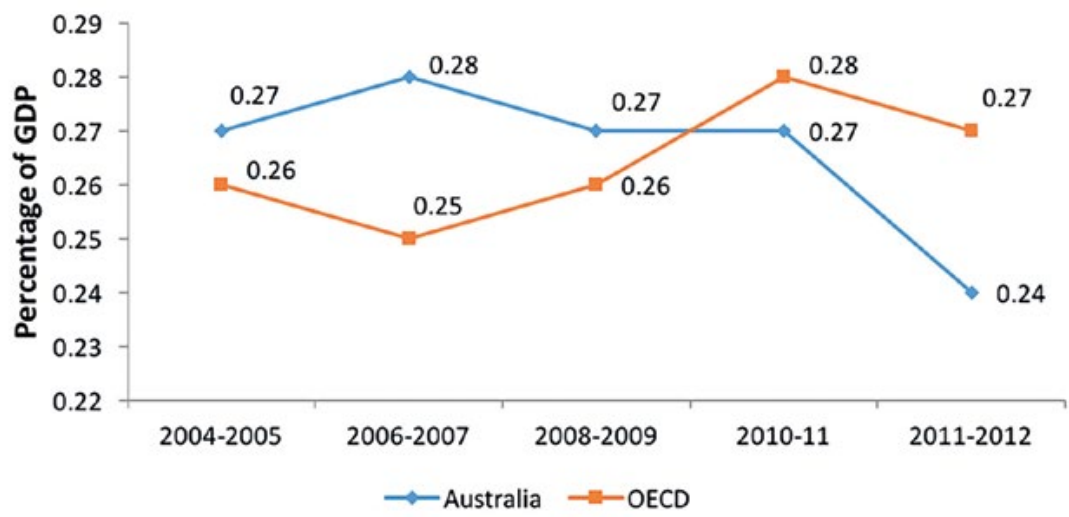

Figure 6: Comparison Australia/OECD government expenditure of research and development (GOVERD)

Australia: There has been a slight decrease in government expenditure between the years 2004 and 2012 of $0.3 \%$. However, Australia is comparative to the OECD average in this area of funding. OECD Average: There has been a small increase of $0.1 \%$ in the 2004-2012 period. Despite this increase, both the OECD average and Australia resource their government research similarly.

Data: Australian Bureau of Statistics. 


\section{Researchers and HDR graduates}

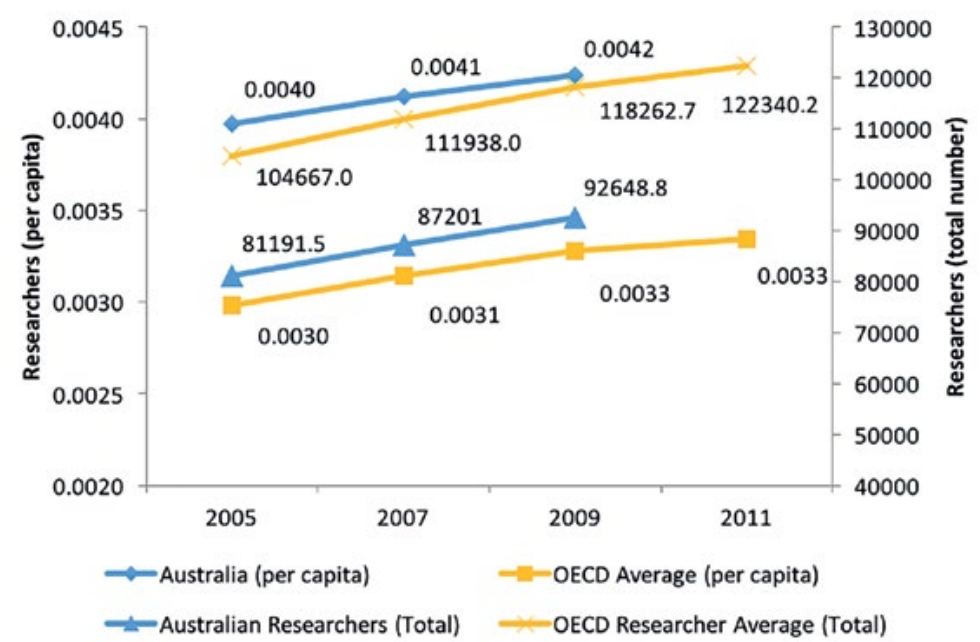

Figure 7: Researchers (full-time equivalent) per capita

Australia: There has been a slight increase in the per capita number of researchers in Australia during the 2005-2011 period. Despite Australia having fewer researchers than the OECD average, it has a greater per capita number of researchers. OECD Average: There has been an greater increase in researchers per capita for OECD countries when compared to Australia $10.003 \%$ to $0.002 \%)$. However, the OECD has a much greater number of researchers but has a lower number of researchers per capita.

Data: OECD Statistics.

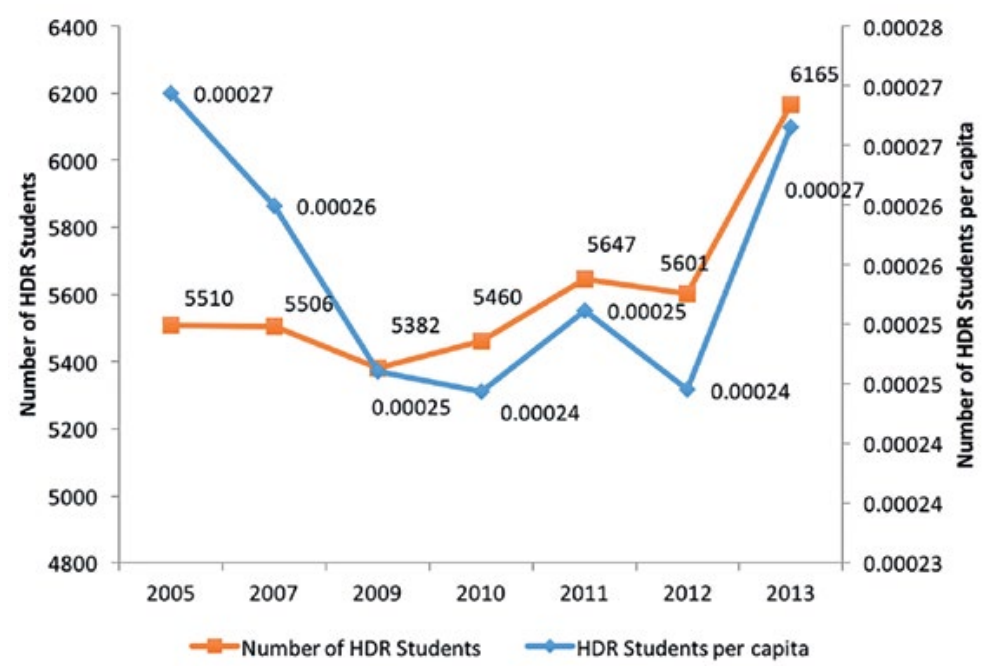

Figure 8: Higher degree by research students (domestic) per capita

Australia: There has been a steady increase in the number of HDR students in Australia in the 20052013 period (increase of 655). Despite this $10 \%$ increase from 2005, the number of HDR students per capita has not changed from the 2005 number, despite the slight variations that occurred. OECD Average: Comparable OECD data was not available.

Data: Office of the Chief Scientist (2012). 


\section{Quality}

\section{Publications}

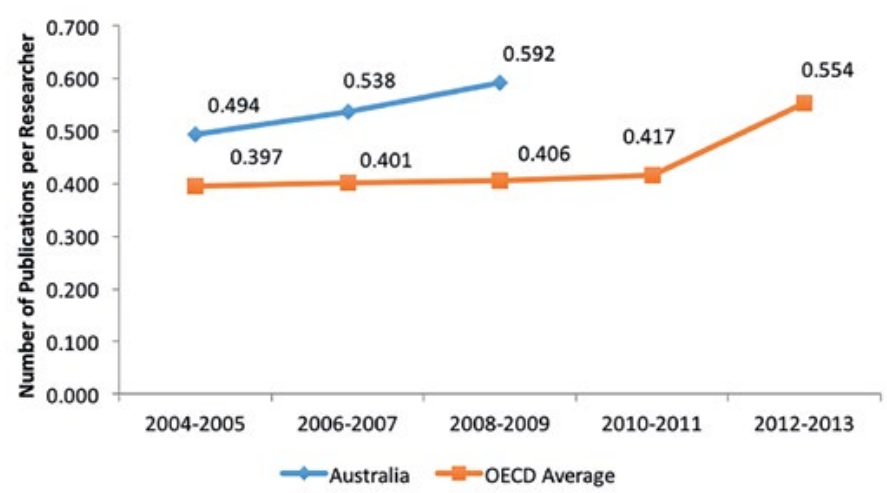

Figure 9: Comparison between OECD and Australia-publications per researcher

Australia: Figure 7 has shown that Australia has a lower number of researchers than the OECD. Furthermore, Figure 1 has shown that Australia invests less money than the OECD in research. Despite this, researchers in Australia have a higher number of publications each year than the OECD average. This indicates that the quality of researchers in Australia is higher than in the OECD. OECD Average: The OECD has seen an increase in publications per researcher in the 2004-2013 period of (0.157). Despite this increase, the 2013 publications per researcher is still lower than the number of publications per researcher in Australia in 2009.

Data: Scimago Labs (Powered by Scopus) and OECD Statistics.

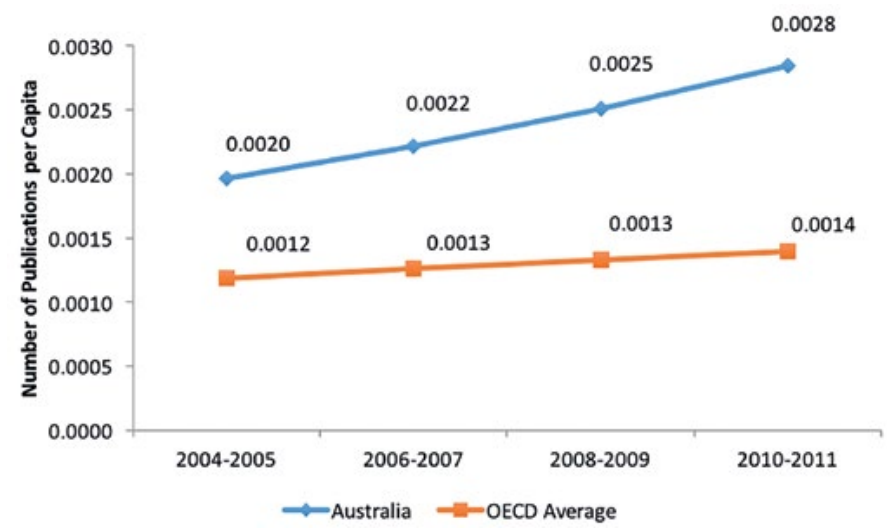

Figure 10: Comparison between OECD and Australia-publications per capita

Australia: Figure 9 has shown that Australia performs highly for the number of publications per researcher. Figure 10 shows that this trend continues for publications per capita. This data is particularly important as it presents a story of how the country itself is doing in regards to publications. Similar to Figure 9, there has been an increase of 0.008 over the 2004-2011 period. Australia publishes double the amount when compared to the OECD average. OECD Average: Figure 10 highlights that despite the higher number of researchers, the OECD has a much lower number of publications. This indicates that the researchers in the OECD are not as proficient at publishing when compared to their Australian counterparts.

Data: Scimago Labs (Powered by Scopus) and OECD Statistics. 


\section{Citations}

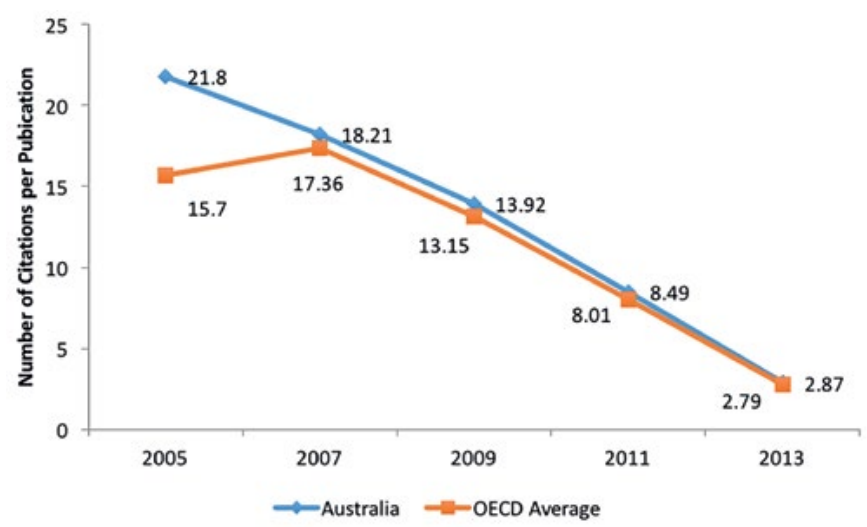

Figure 11: Comparison between OECD and Australia-citations per publication

Australia: Figure 11 shows that Australia has produced more citations per publication over the 2005-2013 period than the OECD. The downward trend between 2005 and 2013 of -18.93 in this eight-year period will not be explained in this article due to the scope of the article itself, but could have resulted in a number of factors such as increase in journal articles and journals available in this time period. OECD Average: The OECD has also seen this downward trend in citations per publications, 12.91 in the 2005-2013 period. This trend may be due to the same reasons as the trend in Australian citations per publications. However, Figure 11 highlights that the quality of publications produced by Australian researchers is greater than those of the OECD.

Data: Scimago Labs (Powered by Scopus) and OECD Statistics.

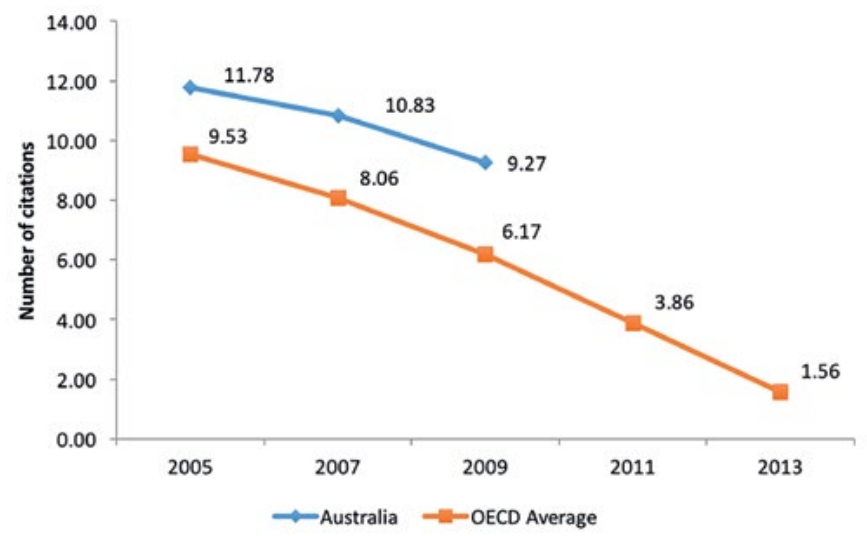

Figure 12: Comparison between OECD and Australia-citations per researcher

Australia: Figure 11 has shown that the publications produced in Australia are of higher quality due to the number of citations. Figure 12 shows that researchers in Australia are also of higher quality due to the citations per researcher. The data is currently incomplete due to the 2009 onwards data being unavailable; however, there has been roughly a $20 \%$ difference in citations when compared to the OECD. The downward trend of citations per publication can be explained by the decrease in citations per publication. OECD Average: The OECD average has decreased at a greater pace than the Australia average citations per researcher. However, as the data is incomplete for the 2009 onwards period for Australia, this may be inaccurate. The downward trend can be explained for the same reasons as the Australian downward trend.

Data: Scimago Labs (Powered by Scopus) and OECD Statistics. 


\section{Engagement}

\section{Industry engagement}

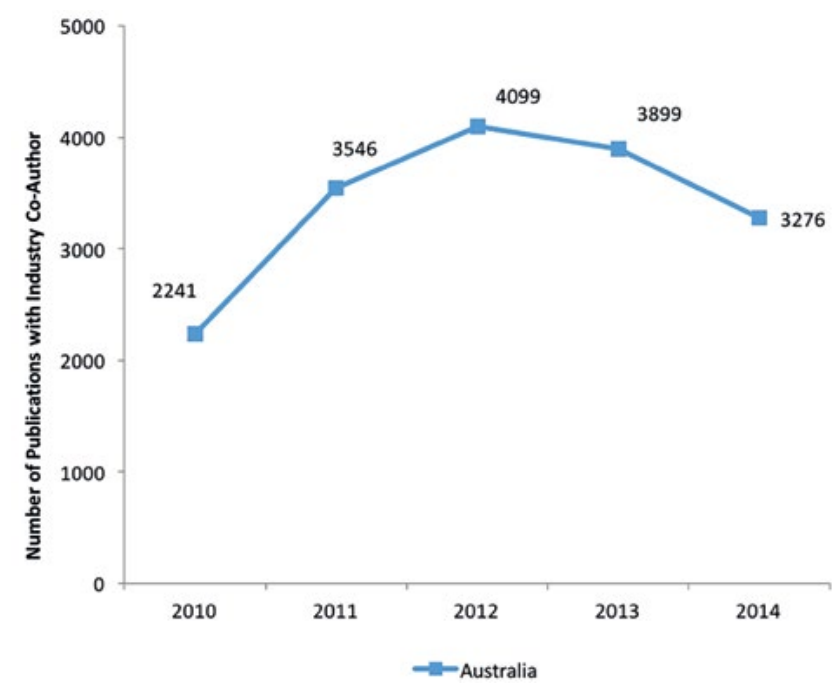

Figure 13: Domestic publications with an industry co-author

Australia: Figure 13 shows the number of publications that feature an industry co-author. This data shows the collaboration between the research sector and the industry sector. The upward trend between 2010 and 2012 was an increase of 1,808 publications, which highlights increased industry collaboration in this period. OECD Average: Comparable OECD data was not available. Data: CSIRO.

\section{International collaboration}

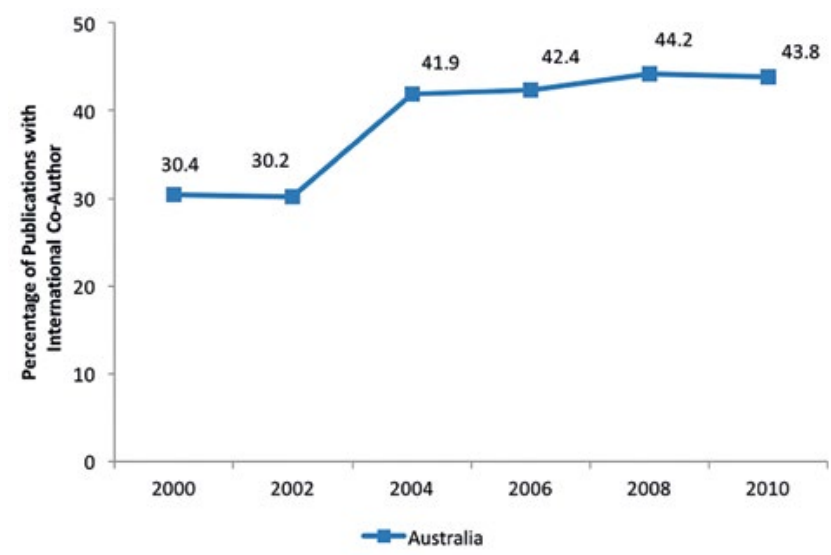

Figure 14: Percentage of publications with at least one international co-author

Australia: Figure 14 shows an increase of $13.4 \%$ in the number of international collaborations between 2000 and 2010. Comparable OECD data was not available, however, due to the nature of international collaboration, this data is most likely comparable to Australia. OECD Average: Comparable OECD data was not available.

Data: Office of the Chief Scientist (2012). 


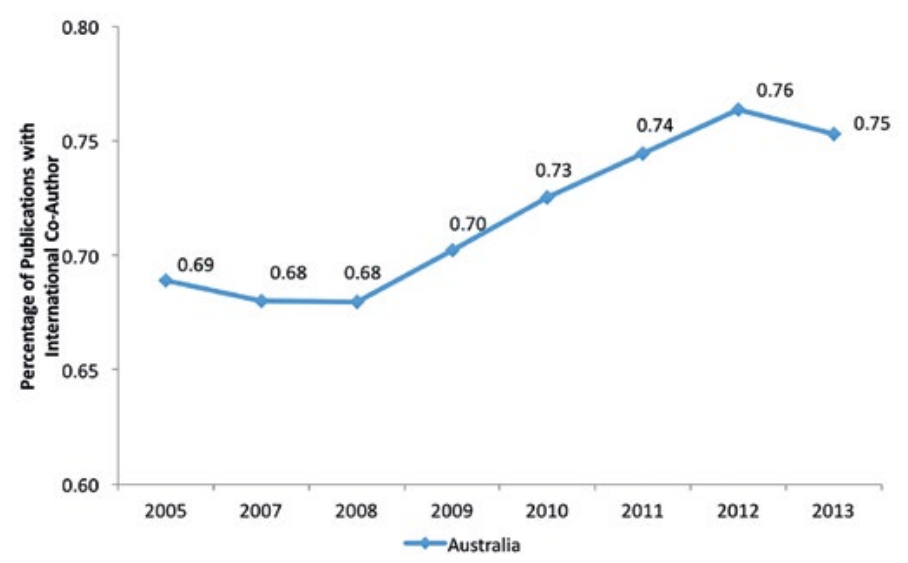

Figure 15: Percentage of world's top 1\% highly cited publications from Australia (attributed to international collaboration)

Australia: Figure 15 shows that with the increase in international collaboration (see Figure 14), there has been an increase in the quality of publication itself. This highlights that international collaboration leads to higher quality publications. OECD Average: Comparable OECD data was not available.

Data: Office of the Chief Scientist (2012).

\section{Return on investment}

\section{Efficiency}

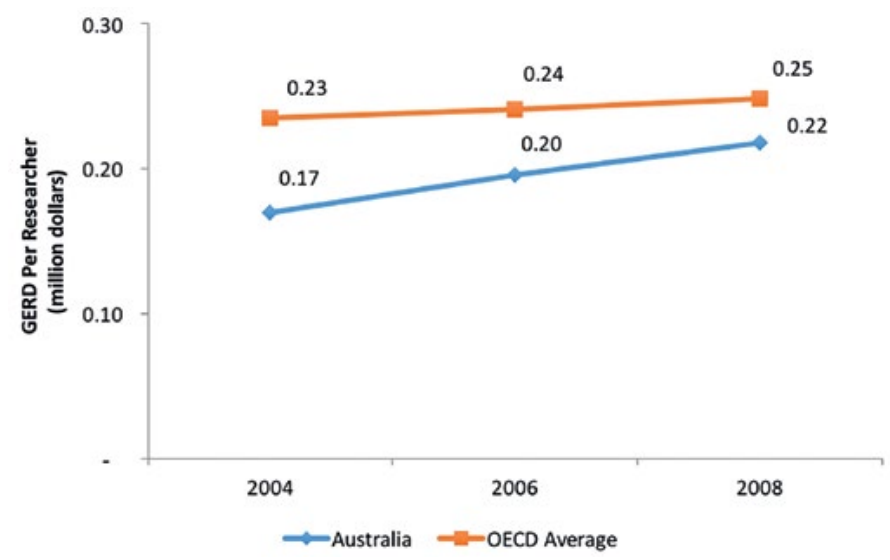

Figure 16: GERD per researcher

Australia: Figure 16 highlights the amount of funding spent on researchers. Despite Australia spending less on researchers, it produces a greater number of publications per researcher (Figure 9) and better quality publications (Figure 11) than counterparts from the OECD. OECD Average: The OECD has slightly higher average investment per researcher than Australia (AU\$0.3 million in 2008, the smallest difference in the 2004-2008 period). However, despite this higher spending, the OECD produces less publications and citations, indicating their researchers are of lower quality than Australia researchers.

Data: OECD Statistics. 


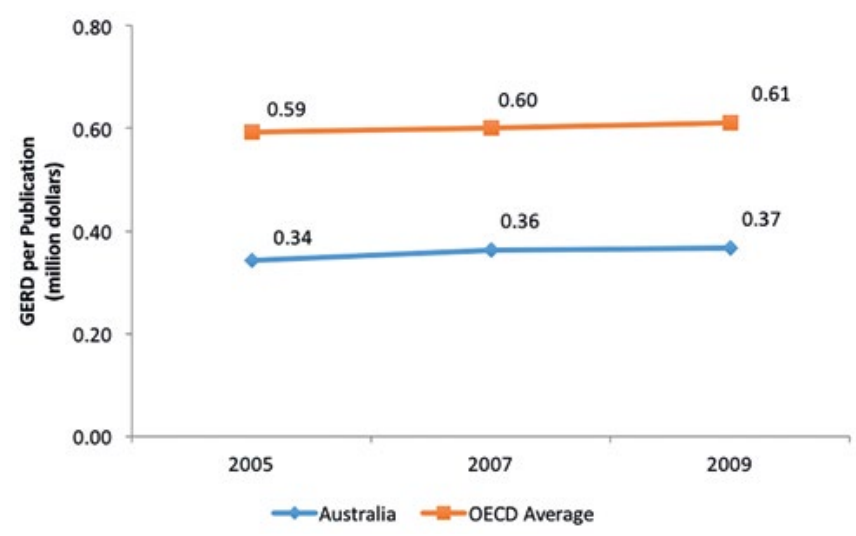

Figure 17: GERD per publication produced

Australia: There has been an insignificant change of 0.03 per cent between 2005 and 2009, which correlates with the increase in GERD generally. Similar to Figure 16, Australia invests less per publication yet produces a higher number of citations than the OECD average. This further showcases that Australian researchers are of higher quality. OECD Average: Figure 17 shows that there has been an insignificant change of 0.005 per cent each year between the years of 2005 and 2009 in spending per publication, which correlates with the increase in GERD generally. The OECD average spent per publication is greater than Australia. This could be due to the higher number of researchers present. Data: Scimago Labs (Powered by Scopus) and OECD Statistics.

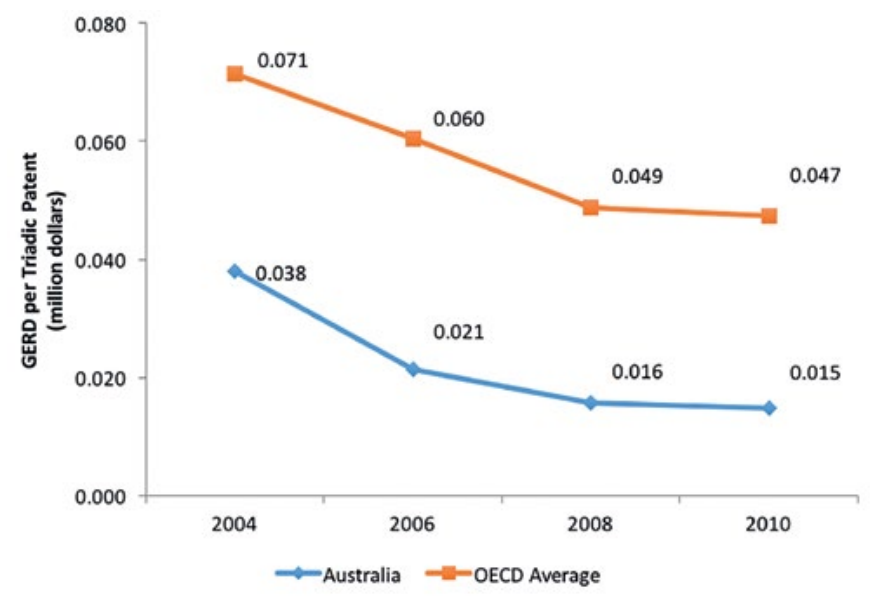

Figure 18: GERD per triadic patent ${ }^{26}$ (patent registered in three different international patent offices) produced

Australia: In the 2004-2010 period, there has been a decrease in the cost per triadic patent (AU\$0.0038 million in 2004 to AU\$0.015 million in 2010). This could be due to a number of factors that will not be explored in this article. Figure 19 shows the number of triadic patents registered. Despite Australia having a smaller number, it costs much less to produce each patent itself. In considering Figure 18 with Figure 16 and Figure 17, it highlights that Australian researchers can produce outcomes with less funding than OECD researchers. OECD Average: Similar to Australia, the cost of producing a triadic patent has decreased in the 2004-2010 period. However, it costs significantly more for the OECD to produce a triadic patent than Australia. (AU $\$ 0.0071$ to AU\$0.038 million in 2004, AU\$0.047 to AU\$0.015 million in 2010).

Data: Scimago Labs (Powered by Scopus) and OECD Statistics.

26 A triadic patent is one registered in three different patent offices internationally. 


\section{Commercialisation}

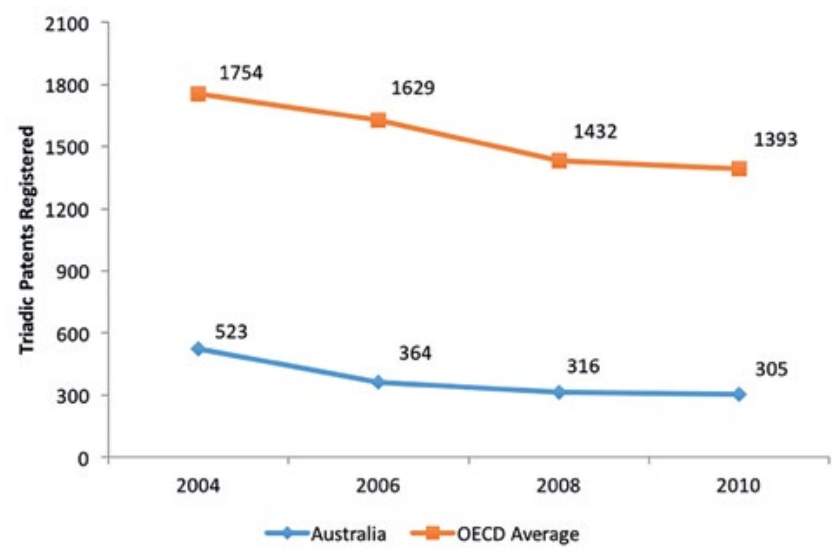

Figure 19: Triadic patents produced

Australia: Figure 19 shows the number of triadic patents produced in the 2004-2010 period. There has been a decrease of 218 from the 2004-2010 period in the number produced. This downward trend will not be explained in this article due to the scope of the project. Figure 18 shows that Australia spends less per triadic patent, and Figure 19 shows Australia produces significantly fewer patents than OECD researchers, which indicates that there is less emphasis on commercialisation of research in Australia. OECD Average: Similar to Australia, there has been a decrease in the number of triadic patents produced. The OECD produced significantly more patents than Australian researchers: triple Australia's rates each year between the 2004-2010 period.

Data: OECD Statistics.

\section{Responsiveness}

\section{National Research Priorities}

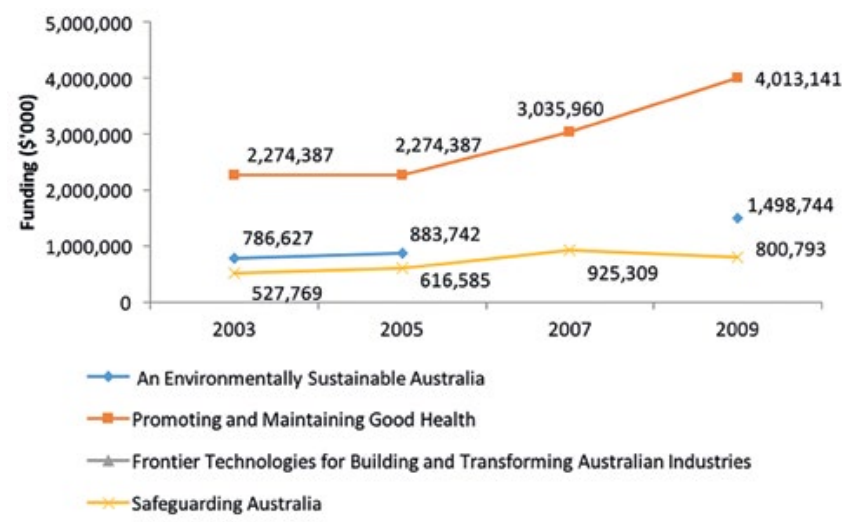

Figure 20: Funding of national research priorities

Australia: Figure 2 shows increase in research funding in all sectors in the past 10 years. Figure 20 shows that with this increase there has been an increase in funding for national priority sciences. There currently is no data available for funding increases for 'Frontier Technologies for Building and Transforming Australian Industries'. OECD Average: No comparable data exists.

Data: Australian Bureau of Statistics. 


\section{Improving the framework for future assessments}

\section{Data recommendations}

This article has portrayed the strengths, weakness, opportunities and threats to the Australian research system based on available data. However, due to the impracticality of data collection and the resourcing required to adequately collect robust data, the presentations made in this article, and hence the assessment of the research system, could be improved.

This article has identified three main aspects of Australia data that could be improved: definitions, consistency and robustness. These aspects will be examined in line with the indicators presented in this article to determine whether existing data should be improved.

The resourcing data is significantly robust in both its collection and definition. The ABS collects GERD and its expenditure breakdown on a yearly basis and allows for a consistent assessment through both a retrospective lens (how much investment was made previously, how much should we invest this year?) and a prospective lens (how much money should we put in this year to get these outcomes?).

The quality data presented in this article was collected through Scopus and the OECD Statistics. Data was not available for the years beyond 2009 in Figure 9 due to the lack of FTE research data beyond 2009. An issue with the publication data is that whilst Scopus collects data on publications from all subject fields, this is not consistent with the definition of publications from other sources, such as CSIRO. Furthermore, other data collection bodies, such as HERDC, ${ }^{27}$ collect publication data on the same definition but only for higher education institutions. Whilst this article has been consistent in its publication data (using publications for all subject areas), it should be noted that publication data is not consistently collected according to the same definition.

The engagement data was broken down into industry engagement and international collaboration. The industry data was provided by CSIRO upon request and the international collaboration data was sourced from the ARC. ${ }^{28}$ Given that the data came from two reputable organisations funded by the Australian Government, this should be proof of the robustness of the data. CSIRO provided a breakdown of the

27 Department of Education and Training, Higher Education Research Data Collection. Reports available from archive.arc.gov.au/file-search/ERA?level_1=ERA\&level_2=2012\&level_3=National\%20Report\&sort=asc\& order $=$ Document $\% 20$ Name.

28 Office of the Chief Scientist (2012), Health of Australian Science Report. Available from www.chiefscientist.gov. au/2012/05/health-of-australian-science-report-2/, p. 140. 
publication data; however, ARC did not, which makes the two difficult to compare, especially against the total number of publications presented. Considering this, Figure 14 was provided by ARC and was not constructed through data mining and comparison. Lastly, the top 1 per cent cited publications data did not define the subject matter or the journal the article was published in. Whilst this may not be an issue, the data would be considered more robust had this been available for consideration.

The return on investment (ROI) data was an amalgamation of data from the OECD and the ABS to determine efficiency. Due to the reliability of these sources, these data are sufficiently robust to support the determinations this article makes. However, due to the lack of recent data (last five years), these conclusions are inappropriate for consideration in 2015. This information is still important, however, as it presents a picture of the efficiency of the system between 2004 and 2010.

Lastly, the responsiveness data presented in Figure 20 came from the ABS, with the definitions from The Australian National University. ${ }^{29}$ The data itself is incomplete for several reasons: national research priorities have not been clearly defined, which makes it difficult to fit funding categories into the priorities themselves; and the priorities have changed in the last five years, which makes the current assessment presented in Figure 20 a dated portrayal.

\section{Conclusion}

The aim of this article was to examine the existing framework for assessing the Australian research system and to develop a more robust framework to provide a holistic approach to this assessment.

A framework was developed using five indicators: resourcing, quality, engagement return on investment and responsiveness. Data was collected on these indicators to present an outlook of the system as a whole.

This article has concluded that Australia has a strong research system that produces high-quality research in the form of strong publications and citations. Whilst it could improve in both engagement and commercialisation, this will come with further increases in funding from all research sectors.

29 Australian National University (n.d.), Australia's research priorities and strengths. Available from mobility.anu. edu.au/incoming/strengths/ (accessed 15 October 2015). 


\section{Bibliography}

\section{Data set sources}

Australian Bureau of Statistics

Commonwealth Scientific and Industrial Research Organisation

Scimago Labs (Powered by Scopus). Available from: www.scimagojr.com/ countryrank.php

\section{Other sources}

Arundel, A. \& Bordoy, C. (2008). Developing Internationally Comparable Indicators for the Commercialisation of Publicly-funded Research, MERIT Working Paper No. 75, United Nations University. Retrieved from econpapers.repec.org/paper/ unmunumer/2008075.htm

ATSE (Australian Academy of Technological Sciences and Engineering) (2015), Research Engagement for Australia: Measuring Research Engagement Between Universities and End-Users. Retrieved from www.atse.org.au/content/ publications/reports/industry-innovation/research-engagement-for-australia. aspx

ATSE (2015). We can Measure Research Engagement. Retrieved from www.atse. org.au/content/publications/media-releases/2015/we-can-measure-researchengagement.aspx

Australian National University. (n.d.). Australia's Research Priorities and Strengths. Retrieved from mobility.anu.edu.au/incoming/strengths/

Australian Research Council and Commonwealth of Australia. The Excellence in Research for Australia (ERA) Initiative. Retrieved from www.education.gov.au/ higher-education-research-data-collection

Chief Scientist of Australia. (2014). Strategic Science and Research Priorities. Retrieved from www.chiefscientist.gov.au/wp-content/uploads/STRATEGIC-SCIENCEAND-RESEARCH-PRIORITIES_181214web.pdf (accessed 3 August 2015).

Cunningham, P. (2014). ERAWATCH Country Reports 2013: United Kingdom, European Commission. Retrieved from rio.jrc.ec.europa.eu/sites/default/files/ riowatch_country_report/ERAWATCH\%20Country\%20Report $\% 20$ UK\%20 2013.pdf 
Department of Education and Australian Government Department of Industry. (2014). Boosting the Commercial Returns from Research. Retrieved from submissions.education.gov.au/Forms/higher-education-research/Documents/ Boosting\%20Commercial\%20Returns\%20from\%20Research\%20\%20-\%20 24102014.pdf

Department of Education and Training, Higher Education Research Data Collection. Reports available from: archive.arc.gov.au/filesearch/ERA?level_1=ERA\&level_2=2012\&level_3=National\%20 Report\&sort=asc\&order=Document $\% 20$ Name

Department of Industry and Science. (2015). National Survey of Research Commercialisation 2015 Review Report. Retrieved from industry.gov.au/ innovation/NSRC/Policy/Documents/Final-NSRC-Review-Report.pdf

Griliches,Z.(1998).RङDandProductivity: TheEconomicEvidence. Chicago:University of Chicago Press. doi.org/10.7208/chicago/9780226308906.001.0001

Higher Education Funding Council for England. (2014). Research Excellence Framework 2014: The Results. Retrieved from www.ref.ac.uk/media/ref/content/ pub/REF\%2001\%202014\%20-\%20full\%20document.pdf

Higher Education Funding Council for England. (2014). The Nature, Scale and Beneficiaries of Research Impact: An Initial Analysis of Research Excellence Framework (REF) 2014 Impact Case Studies. Retrieved from www.hefce.ac.uk/ pubs/rereports/Year/2015/analysisREFimpact/

OECD Innovation Policy Platform. (n.d.). OECD Issue Brief: Research Organisation Evaluation. Retrieved from www.oecd.org/innovation/policyplatform/48136330. pdf (accessed 1 October 2015).

Office of the Chief Economist and Department of Industry. (2012). Australian Innovation System Report 2012. Retrieved from industry.gov.au/Office-of-theChief-Economist/Publications/Policy/AustralianInnovationSystemReport/ AISReport2012.pdf

Office of the Chief Economist and Department of Industry. (2014). Australian Innovation System Report 2014. Retrieved from industry.gov.au/Office-of-theChief-Economist/Publications/Documents/Australian-Innovation-System/ Australian-Innovation-System-Report-2014.pdf

Office of the Chief Scientist. (2012). Health of Australian Science Report. Retrieved from www.chiefscientist.gov.au/2012/05/health-of-australian-science-report-2/

Redden, E. (2013). Methodology of QS rankings Comes under Scrutiny. Retrieved from www.insidehighered.com/news/2013/05/29/methodology-qs-rankingscomes-under-scrutiny (accessed 3 October 2015). 
Ryan, B. (2015). Developing an International Commercialisation Ranking for Universities. Australian National University: Canberra.

Shin, J. \& Toutkoushian, R. (2011). 'The Past, Present and Future of University Rankings'. In J. Shin, R. Toutkoushian \& T. Ulrich (eds), University Rankings in The Changing Academy: The Changing Academic Profession in International Comparative Perspective. Springer: Netherlands. doi.org/10.1007/978-94-0071116-7_1

The Center for Measuring University Performance. (2012). The Top American Research Universities Annual Report 2012. Retrieved from mup.asu.edu/sites/ default/files/mup-pdf/MUP-2012-Top-American-Research-UniversitiesAnnual-Report.pdf 
This text is taken from The ANU Undergraduate Research Journal, Volume Eight, 2016, edited by Daniel McKay, published 2017 by ANU eView, The Australian National University, Canberra, Australia.

dx.doi.org/10.22459/AURJ.08.2016.17 